\title{
Herbivorous insect decreases plant nutrient uptake: the role of soil nutrient availability and association of below-ground symbionts
}

Authors: Noboru Katayama*a,b, Alessandro Oliveira Silva ${ }^{a}$, Osamu Kishida ${ }^{b}$, Masayuki Ushio $^{\text {a }}$, Satoshi Kita ${ }^{\mathrm{c}}$ and Takayuki Ohgushi ${ }^{\mathrm{a}}$

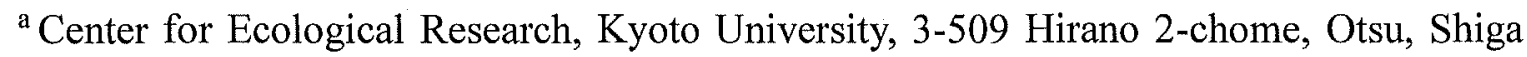
520-2113, Japan

${ }^{\mathrm{b}}$ Field Science Center for Northern Biosphere, Hokkaido University, Toikanbetsu 131, Horonobe-cho, Hokkaido 098-2943, Japan

c Laboratory of Forest Ecology, Faculty of Agriculture, Kyoto University, Kitashirakawa-Oiwake-cho, Sakyo-ku, Kyoto 606-8502, Japan

${ }^{*}$ Corresponding author: Noboru Katayama

Field Science Center for Northern Biosphere, Hokkaido University, Toikanbetsu 131, Horonobe-cho, Hokkaido 098-2943, Japan

E-mail: noborukata1913@gmail.com

Phone: $+81-1632-6-5211$

Fax: $+81-1632-6-5003$

Author Contributions: NK and AOS originally formulated the idea, and OK and TO developed methodology. NK and AOS performed the experiments, and NK, MU and SK analyzed plant and soil chemicals. NK wrote the manuscript, and OK and TO provided editorial advice. 


\begin{abstract}
1. Plants take nutrients from rhizosphere via two pathways: (1) by absorbing soil nutrients directly via their roots, and (2) indirectly via symbiotic associations with nutrient-providing microbes. Herbivorous insects can alter these pathways by herbivory, adding their excrement to the soil, and affecting plant-microbe associations.
\end{abstract}

2. Little is known, however, about the effects of herbivorous insects on plant nutrient uptake. We carried out greenhouse experiments with soybean, aphids, and rhizobia to examine the effects of aphids on plant nutrient uptake.

3. First, we compared the inorganic soil nitrogen and the sugar in aphid honeydew between aphid-infected and -free plants. We found that aphid honeydew added $41 \mathrm{~g}$ $\mathrm{m}^{-2}$ of sugar to the soil, and that aphids decreased the inorganic soil nitrogen by $86 \%$. This decrease may have been caused by microbial immobilization of soil nitrogen followed by increased microbial abundance due to aphid honeydew.

4. Second, we compared nitrogen forms in xylem sap between aphid-infected and -free plants to examine nitrogen uptake. Aphids decreased the nitrogen uptake via both pathways, and strength of the impact on direct uptake via plant roots was greater than indirect uptake via rhizobia. The reduced nitrogen uptake by the direct pathway was due to microbial immobilization, and that by the indirect pathway was likely due to the interaction of microbial immobilization and carbon stress, which was caused by aphid infection.

5. Our results demonstrate that herbivorous insects can negatively influence the two pathways of plant nutrient uptake and alter their relative importance.

Keywords honeydew, microbial immobilization, nitrogen, rhizobia, soybean, xylem sap 
analysis 


\section{Introduction}

Nutrient uptake by plants is a fundamental ecosystem process that determines both the biomass and properties of the plants and thus dictates the dynamics of organisms that utilize them (Wardle, 1992). Plant roots absorb soil nutrients directly from the soil, and plants also take up soil and atmospheric nutrients indirectly via symbiotic interactions with microbes in the rhizosphere (Smith \& Read, 1997; Patriarca et al., 2002). These two nutrient uptake pathways have been intensively but separately studied. Recently, researchers have begun to assess the relative importance of these two pathways (Wardle, 2002; Wardle et al., 2004) and interactions between them. For example, nutrient uptake via microbial symbionts may decrease with increasing the amount of soil nutrients (Katayama et al., 2010). Although previous studies have documented the spatial and temporal variations in nutrient uptake by plants (Smith \& Read, 1997; Dessureault-Rompré et al., 2007), factors affecting nutrient uptake via the two pathways and their relative importance have received little attention. It is critical to examine these factors, to deepen our understanding of plant nutrient dynamics and to gain insight into nutrient cycling between above- and below-ground ecosystem components.

Insects are a dominant component of terrestrial ecosystems, in terms of abundance and biodiversity (Schowalter, 2000), but their importance in controlling ecosystem functions (e.g., decomposition and nutrient cycling) has long been overlooked; recently researchers have begun to pay more attention to the roles that insects play in ecosystem functioning (Weisser \& Siemann, 2004). In particular, herbivorous insects affect decomposition processes by influencing the quantity and quality of plant litter, and their excrement adds nutrients to the soil (Hunter, 2001; Wardle, 2002; Frost \& Hunter, 2004; Schweitzer et al., 2005; Kay et al., 2008). Herbivorous insects frequently increase the tannin content of plant litter, which inhibits microbial activity and thus indirectly 
slows the decomposition rate (Chapman et al., 2003; Schweitzer et al., 2005; Kay et al., 2008). Several studies examining how herbivorous insects affect nutrient uptake by plants have focused on the direct absorption of soil nutrients by plant roots (Stadler et al., 1998; Frost \& Hunter, 2004). Insect excrement (i.e., frass or honeydew) in the soil also contains nutrients that can be utilized by plants after mineralization (Weisser \& Siemann, 2004). Because insect frass contains high concentrations of labile carbon (sugars) and nitrogen (ammonium and nitrate) (Wardle, 2002), it can either accelerate or decelerate nitrogen mineralization, depending on the $\mathrm{C} / \mathrm{N}$ ratio of the frass (Kagata \& Ohgushi, 2012). Nitrogen-rich frass can accelerate nitrogen mineralization and thus increase the inorganic nitrogen content of the soil, whereas nitrogen-poor frass can slow the rate of nitrogen mineralization by inducing microbial nitrogen immobilization: an increase in belowground microbial biomass that take up inorganic nitrogen from the soil (Kagata \& Ohgushi, 2012). Because the amount of frass added to the soil is often large (Seastedt \& Crossley, 1984; Stadler et al., 2004) and its effect on soil nutrient dynamics becomes apparent within a few days (Lovett \& Ruesink, 1995; Hunter, 2001), frass can be an important factor determining nutrient uptake dynamics in plants (Frost \& Hunter, 2004).

Herbivorous insects also influence nutrient uptake by plants through their effects on plant associations with microbial symbionts. Insect herbivory can either positively or negatively affect colonization and metabolic activity of microbial symbionts on plant roots (Gehring \& Whitham, 1994; Nishida et al., 2009) by two mechanisms. First, insect herbivory changes the nutrient status of plants (Karban \& Baldwin, 1997; Ohgushi, 2005). When herbivorous insects consume plant tissues, the plants cannot adequately reward symbionts with photosynthetic carbon, thus decreasing symbiont activity. Because symbionts need photosynthetic carbon to be active, insect herbivory may decrease the activity of the symbionts. The second mechanism concerns an effect of nutrients adding to 
the soil in insect excrement (Hunter, 2001). Strength of plant-symbiont associations weakens with increasing soil nutrients because the plants are able to obtain enough nutrients directly from the soil (Katayama et al., 2010). Since insect frass can increase or decrease inorganic soil nutrients (Kagata \& Ohgushi, 2012), we expect that the frass influences the nutrient flow from the symbionts to the host plants.

This study had two objectives. First, we aimed to examine the effects of herbivorous insects on plant nutrient uptake via the two pathways: direct absorption from the soil by plant roots and indirect uptake via associated symbionts. Our second objective was to determine whether and how herbivorous insects changed the relative importance of these two pathways. For this purpose, we conducted greenhouse experiments with a model system consisting of a soybean (Glycine max (L.)) and soybean aphids (Aphis glycines Matsumura), which is a suitable system for investigating the relative importance of the two hypothesized nutrient uptake pathways for the following reasons (Dixon, 1998; Stadler et al., 2004): (1) the soybean has a mutualistic association with rhizobia that provide nitrogen to the plant, (2) the aphids are a dominant herbivore on the soybean, and (3) the aphids excrete sugar-rich honeydew, which may influence the soil nutrient dynamics.

We hypothesize that the honeydew excreted by the aphids decreases the inorganic nitrogen content of the soil: because the abundance of free-living below-ground microbes is often labile-carbon limited, the addition of honeydew to the soil may increase the abundance of such microbes and thus indirectly decrease the soil inorganic nitrogen content to decrease by microbial immobilization (Dighton, 1978; Grier \& Vogt, 1990; Stadler et al., 2004). Thus, the honeydew addition is likely to decrease nitrogen uptake from the soil by plants. In contrast, it may increase the nitrogen uptake via rhizobia, because when soil inorganic nitrogen is low, plants depend more on rhizobia for nitrogen 
(Katayama et al., 2010). Alternatively, we hypothesize that aphids may decrease plant nitrogen uptake via rhizobia. Photosynthetic carbon is necessary for plants to maintain an association with rhizobia. However, aphids, may produce carbon stress in plants by consuming photosynthetic carbon (Macedo et al., 2003), causing the plants to have difficulty maintaining the rhizobial association. Our system enables to verify these hypotheses by separately measuring nitrogen derived from rhizobia and soil (Giller, 2001). Soybean xylem sap contains three forms of nitrogen: ureides (allantoin and allantoic acid), amino acids (mainly asparagine and glutamine), and nitrate (Matsumoto et al., 1977). Nitrogen derived from rhizobia is transformed into ureides in root nodules, and is transported through xylem vessels (Streeter, 1979), whereas nitrogen absorbed from the soil is mainly transported in the form of nitrate and amino acids (Thomas \& Sodek, 2006).

We carried out two experiments to test these hypotheses. The first experiment quantified the amounts of sugars from honeydew and inorganic nitrogen in soil between treatments with and without aphids on potted soybean plants. The second experiment measured the amounts of nitrogen $(\mathrm{N})$ in the form of ureides (ureide- $\mathrm{N}$, primary form of rhizobia-derived nitrogen) and nitrate and amino acid (nitrate- $\mathrm{N}$ and amino acid- $\mathrm{N}$, nitrogen absorbed mainly from the soil) in plants with and without aphids. Then, we discuss how the aphids affects the plant uptake of nitrogen via the two pathways.

\section{Materials and Methods}

\section{Materials}

Soybean, Glycine $\max (\mathrm{L}$.$) , is an annual leguminous plant native to East Asia. In$ central Japan, seeds germinate in late June to early July, and the plant flowers in August. Soybean plants begin to produce pods in September, and pods gradually mature during autumn. Several symbiotic bacterial species, including Bradyrhizobium japonicum, $B$. 
elkani, and Rhizobium fredii, form root nodules on soybean roots.

One of the dominant insect herbivores on soybean in Japan is the soybean aphid, Aphis glycines Matsumura (Hemiptera: Aphididae). The aphid overwinters as eggs and hatch in spring (Wang et al., 1962). It feeds on phloem sap from stems and leaves. The developmental time from first instar to adult is $7-10$ days in an outdoor climate chamber (25 ${ }^{\circ} \mathrm{C}$, natural light conditions) (A. O. Silva, personal observation). The aphid has approximately 15 generations per year in a soybean field, and population often exceeds 1000 individuals on a single soybean seedling (A. O. Silva, personal observation).

In March 2008, we inoculated one clone of soybean aphids to potted soybeans in an outdoor climate chamber $\left(25^{\circ} \mathrm{C}\right.$; photoperiod, $\left.12 \mathrm{~L}: 12 \mathrm{D}\right)$. The aphids were provided by the Laboratory of Applied Entomology, Faculty of Agriculture, Utsunomiya University, Tochigi Prefecture, Japan, and maintained for two years. To maintain the aphid colony, we sowed at least 100 pre-germinated seeds of soybean individually in polyethylene pots ( 7 $\mathrm{cm}$ in diameter, $7 \mathrm{~cm}$ in depth) containing non-sterilized soil (Hana To Yasai No Baiyoudo $^{(\mathbb{B}}$, Tachikawa Heiwa Nouen Co., Ltd.) every two weeks, and cultivated them in an outdoor climate chamber $\left(25^{\circ} \mathrm{C}\right.$ and natural light $)$. After two weeks, we prepared eight plastic cages $(30 \mathrm{~cm} \times 40 \mathrm{~cm} \times 30 \mathrm{~cm}$ deep), and placed 12 potted seedlings in each plastic cage $(30 \mathrm{~cm} \times 40 \mathrm{~cm} \times 30 \mathrm{~cm}$ deep). We inoculated $10-20$ aphids to the soybean seedlings per cage, which was covered with a plastic net to prevent the aphids from escaping put in an incubator $\left(25^{\circ} \mathrm{C}\right.$; photoperiod, 16L:8D). After two weeks, we collected aphids from the cages and released 10-20 aphids into each of eight other cages with 12 new seedlings obtained as described above. We repeated this procedure for 2 years.

\section{Experiment 1: effect of aphids on soil inorganic nitrogen}


Experiment 1 was designed to evaluate the effect of aphids on the concentrations of total and inorganic nitrogen in the soil of the pots with soybean plants. We also measured the sugar content of the honeydew excreted by aphids during this experiment.

\section{Experimental design}

On 22 September 2008, 200 soybean seeds were sown individually in polyethylene pots $(7 \mathrm{~cm}$ in diameter, $7 \mathrm{~cm}$ in depth) containing non-sterilized soil (Hana To Yasai No Baiyoudo ${ }^{\circledR}$ ). After two weeks, we transplanted each seedling into a large polyethylene pot $(20 \mathrm{~cm}$ in diameter, $20 \mathrm{~cm}$ in depth, each containing $5 \mathrm{~L}$ of soil). Seedlings were grown in an outside temperature-controlled greenhouse $\left(25^{\circ} \mathrm{C}\right.$ and natural light conditions) until the beginning of the experiment.

On 29 October 2008, we selected 10 potted plants in similar size, and inoculated 1000 aphids to each of five plants (aphid-infected treatment), and the remaining five plants were cultivated without aphids as the control (aphid-free) treatment. Each pot was covered with a nylon net (mesh size, $1 \mathrm{~mm}$ ) to prevent dispersal of the aphids and colonization by other insects. We inserted 90 -cm-long plastic sticks supported by three wire rings into each pot to hold the net. We placed the pots of the two treatments randomly in three rows in an outdoor climate chamber $\left(25^{\circ} \mathrm{C}\right.$ and natural light conditions). The rows were spaced $50 \mathrm{~cm}$ apart, and the pots within each row were spaced $20 \mathrm{~cm}$ apart. All plants were adequately watered every day.

We counted the number of aphids on each plant one every week to maintain a fixed number (1000 individuals), and used a fine-bristle brush to remove any additional aphids, with being careful to not drop the aphids. One every week, we randomly rearranged the rows of pots to minimize microhabitat effects.

Two and four weeks after the aphid inoculation, we placed a wire ring $(20 \mathrm{~cm}$ in 
diameter, $3.14 \times 10^{-4} \mathrm{~m}^{2}$ in area) covered with an aluminium foil disc $5 \mathrm{~cm}$ above the soil surface on each pot for collecting honeydew. After $24 \mathrm{~h}$, we removed the disc and put it in a nylon bag. The nylon bag was stored in the laboratory at room temperature. Within $24 \mathrm{~h}$ after the discs with honeydew had been collected, each disc was rinsed three times with 5 $\mathrm{mL}$ of xylose solution $\left(0.05 \mu \mathrm{g} \mu \mathrm{L}^{-1}\right)$ (i.e., a total of $15 \mathrm{~mL}$ of xylose solution per sample). The rinsing solution was filtered through a Millipore filter $(0.20 \mu \mathrm{m})$, and $1.0 \mathrm{~mL}$ of the filtered solution was transferred to a $1.5-\mathrm{mL}$ tube. The samples of filtered solution were kept in a freezer at $-20^{\circ} \mathrm{C}$ until chemical analysis.

One month after the aphid inoculation, we used a vinyl chloride coring tube with a diameter of $2 \mathrm{~cm}$ to collect the top $5 \mathrm{~cm}$ of soil (about $10 \mathrm{~g}$ ) in each pot. Each soil sample was put in a nylon bag $(14 \mathrm{~cm}$ long $\times 10 \mathrm{~cm}$ wide $)$ and stored at $-20{ }^{\circ} \mathrm{C}$ until chemical analysis.

\section{Chemical analysis of aphid honeydew}

Sugar concentrations in the collected honeydew were analysed by high-performance liquid chromatography, using a Wakosil 5 $\mathrm{NH}_{2}-\mathrm{MS}$ packed column (4.6 x $150 \mathrm{~mm}$; Wako Pure Chemical, Osaka, Japan) and an $80 \%$ acetonitrile mobile phase at room temperature. The flow rate was $1 \mathrm{~mL} \mathrm{m^{-1 }}$. Peak sizes of the different types of sugar present in the honeydew were determined using a refractive index detector (RID; Shimadzu Corp., Kyoto, Japan). Honeydew samples were optimized using seven sugar standards (xylose, fructose, glucose, sucrose, maltose, trehalose, and melezitose), and the composition of each sample was tentatively determined by comparing the retention times with those of a standard sample measured on the same day. The concentrations of the sugars in honeydew were then corrected according to the internal standard (xylose). 
Soil chemical analysis

After manual removal of the organic matter in the collected soil, we added $5 \mathrm{~g}$ of each soil sample to a polypropylene bottle (volume, $100 \mathrm{~mL}$ ) containing $50 \mathrm{~mL}$ of $\mathrm{KCl}$ solution $(1.5 \mathrm{~N})$. The bottle was shaken for $12 \mathrm{~h}$ at $200 \mathrm{rpm}$, and then the solution was filtered through a No. 2 Whatman filter. The chemical composition was determined using an ammonium and nitrate analyser (FUTURA, Alliance Instruments, Cedex, France) to measure the concentration of inorganic nitrogen (i.e., ammonium- $\mathrm{N}+$ nitrate- $\mathrm{N}$ ) in the soil samples. The remaining soil was freeze-dried for total nitrogen analysis. We sieved the samples through an $1 \mathrm{~mm}$ mesh to remove debris and litter, and determined the total nitrogen concentration in $200 \mathrm{mg}$ of dry soil using an elemental analyser (CHN Corder MT-3, Yanaco, Kyoto, Japan).

\section{Experiment 2: effect of aphids on nitrogen uptake via the two pathways}

We determined how much of the nitrogen in the soybean plant had been absorbed directly from the soil and how much was obtained via rhizobia by analysing the contents of the different forms (ureide-N, amino acid-N, and nitrate-N; "ureide assay") of nitrogen in the xylem sap of plants cultivated with and without aphids. Although amino acids are found in xylem sap of nodulated soybeans in nitrogen-free soil, the majority of amino acid-N (more than 80\%) in xylem sap is derived from soil (McClure \& Israel, 1979). Thus, the "ureide assay" can evaluate the relative contribution of $\mathrm{N}$-fixation by rhizobia (Giller, 2001; see Introduction).

\section{Experimental design}

On 23 July 2009, 200 soybean seeds were sown individually in polyethylene pots ( $7 \mathrm{~cm}$ in diameter, $7 \mathrm{~cm}$ in depth) containing non-sterilized soil (Hana To Yasai No 
Baiyoudo $\left.{ }^{\circledR}\right)$. Two weeks later, we transplanted individual seedlings into large polyethylene pots $(20 \mathrm{~cm}$ in diameter, $20 \mathrm{~cm}$ in depth, containing $5 \mathrm{~L}$ soil). The seedlings were grown in an outside greenhouse covered with a nylon netting (mesh size, $2 \mathrm{~mm}$ ) until the beginning of the experiment.

On 4 August 2009, we selected 20 plants in a similar size. We inoculated 1000 aphids to 10 plants (aphid-infected plants), and used 10 non-inoculated plants as the control (aphid-free plants). Each pot was covered with a nylon net (mesh size, $1 \mathrm{~mm}$ ) to prevent dispersal of the aphids and colonization by other insects. The net was supported by three wire rings on $90-\mathrm{cm}-$ long plastic sticks inserted into the pot.

To maintain the fixed number (1000 aphids) set at the beginning of the experiment, we counted the aphid number on each plant once a week and removed additional aphids with a fine-bristle brush.

One month after the inoculation with aphids, we clipped the plants at $5 \mathrm{~cm}$ above ground level and covered the cut surface of the stem with $1 \mathrm{~g}$ of cotton wool wrapped in cellophane film to prevent evaporation of the xylem sap. After $5 \mathrm{~h}$, the cotton wool was removed from each plant and weighed. We collected the xylem sap from the cotton by placing the cotton in a $100 \mathrm{~mL}$ centrifuge tube and centrifuging it at $1300 \times g$ force for $1 \mathrm{~h}$. We then determined the xylem sap flow by a following formula:

Xylem sap flow $\left(\mathrm{g} \mathrm{h}^{-1}\right)=[$ cotton weight after $5 \mathrm{~h}(\mathrm{~g})$ - initial cotton weight $(\mathrm{g})] / 5 \mathrm{~h}$

The collected xylem sap samples were filtered through a Millipore filter $(0.20$ $\mu \mathrm{m})$, transferred into $1 \mathrm{~mL}$ tubes, and stored in a freezer at $-20^{\circ} \mathrm{C}$ until chemical analysis. A separate $50 \mu \mathrm{L}$ subsample of xylem sap was used to determine the amount of each form of nitrogen. Ureide- $\mathrm{N}$, amino acid- $\mathrm{N}$, and nitrate- $\mathrm{N}$ were determined using the 
Young-Conway method (Young \& Conway, 1942), the ninhydrin method (Herridge, 1984), and Cataldo's method (Cataldo et al., 1975), respectively. We were unable to analyse the nitrogen composition one aphid-free and four aphid-infected plants because each of the collected sample volume was less than $150 \mu \mathrm{L}$.

\section{Statistical analysis}

Repeated measures ANOVA was used to compare the total amount of sugar on the aluminium foil discs between aphid-free and aphid-infected treatments. To meet parametric assumptions, the values were $\log (n+1)$-transformed. The concentrations of total soil nitrogen and inorganic soil nitrogen (ammonium- $\mathrm{N}+$ nitrate- $\mathrm{N}$ ), xylem sap flow during the $5 \mathrm{~h}$, and concentrations of soil-derived nitrogen (nitrate- $\mathrm{N}+$ amino acid-N) and rhizobia-derived nitrogen (ureide-N) in xylem sap were compared between treatments by t-tests. To examine the relative impact of aphids on the direct and indirect pathways of nitrogen uptake, MANOVA was performed using the concentrations of soil-derived nitrogen and rhizobia-derived nitrogen in xylem sap as dependent variables. A significant interaction between "aphid effect" and "nitrogen type" means that the aphids influence the relative impacts of the two nutrient uptake pathways.

We determined the magnitude of the aphid effect on the amount of each form of nitrogen by calculating the $\log$ response ratio (i.e. $\ln [$ treatment/control]), which is widely used to compare effect magnitudes in manipulation experiments (Hedges et al., 1999): $\ln ($ treatment/control $)<0$ means that the effect is negative relative to the control effect, and $\ln ($ treatment/control $)>0$ means that the effect is positive. Separate bootstrap models were used to calculate mean and $95 \%$ CL of the log response ratios of soil- and rhizobia-derived nitrogen from 9,999 resampling iterations in each bootstrap model. 


\section{Results}

\section{Sugar content of honeydew and inorganic nitrogen content of the soil}

We identified six forms of sugar on the aluminium foil discs: fructose (mean $\pm \mathrm{SD}$, $24.8 \pm 4.7 \% \mathrm{w} / \mathrm{w})$, glucose $(17.4 \pm 7.4 \%)$, sucrose $(23.7 \pm 5.4 \%)$, maltose $(6.4 \pm 4.9 \%)$ trehalose $(3.0 \pm 3.8 \%)$, and melezitose $(24.7 \pm 6.9 \%)$. The total sugar amount differed significantly between treatments, although the sugar amount after four weeks was less than after two weeks (repeated measures ANOVA: time, $F_{1,8}=17.00, P<0.001$; aphid, $F_{1,8}=303.16, P<0.001$; time $\times$ aphid, $F_{1,8}=16.25, P=0.004$; Fig. 1 ). While the sugar amount in the aphid-free treatment was very low $(<0.12 \mathrm{mg})$ after both two and four weeks, 20.6 and $6.0 \mathrm{mg}$ of sugar was detected in the aphid-infected treatment after two and four weeks, respectively. It suggests that the sugars in the aphid-infected treatments were derived from honeydew excreted by the aphids.

The total soil nitrogen concentration did not differ between treatments ( $t$-test: $t_{8}=$ 1.24, $P=0.251$; Fig. 2a), but the inorganic soil nitrogen (ammonium-N + nitrate- $\mathrm{N}$ ) concentration in the aphid-free treatment was 7.2 times greater than the aphid-infected treatment ( $t$-test: $t_{8}=2.72, P=0.026$; Fig. $\left.2 \mathrm{~b}\right)$.

\section{Soybean nitrogen derived from soil and rhizobia}

Although aphids did not affect the xylem sap flow during a $5 \mathrm{~h}$ collection period $\left(t\right.$-test: $t_{18}=1.52, P=0.147$; Fig. $\left.3 \mathrm{a}\right)$, we detected a significant aphid effect on nitrogen uptake by the plants (MANOVA: $F_{1,13}=8.64, P=0.012$; Fig. $3 b$ ). Also, there was a significant difference, in amount between nitrogen forms (MANOVA: $F_{1,13}=14.56, P<$ 0.001). Although the aphids did not affect the nitrate- $\mathrm{N}$ concentration (aphid-free: $0.011 \pm$ 0.004 (mean $\pm \mathrm{SE}$ ) $\mathrm{mg} \mathrm{mL}^{-1}$, aphid-infected: $0.019 \pm 0.005 \mathrm{mg} \mathrm{mL}^{-1} ;$-test: $t_{13}=1.43, P=$ 
0.176), we detected a significant decrease in the amino acid-N concentrations in xylem sap (aphid-free: $0.47 \pm 0.05 \mathrm{mg} \mathrm{mL}^{-1}$, aphid-infected: $0.24 \pm 0.05 ; t$-test: $t_{13}=12.13, P=$ 0.004), indicating a significant decrease in nitrogen uptake from soil (nitrate- $\mathrm{N}+$ amino acid-N: $t$-test, $t_{13}=3.29, P=0.006 ;$ Fig, $3 b$ ). Similarly, the aphids decreased rhizobia-derived nitrogen (ureide-N: $t$-test, $t_{13}=2.69, P=0.019$; Fig. $3 \mathrm{~b}$ ). A significant interaction between "aphid effect" and "nitrogen type" suggests that the aphids influenced the relative impacts of the two nutrient uptake pathways (MANOVA: $F_{1,13}=5.601, P=$ 0.034; Fig. 3b). The magnitude of the negative effect of aphids on the direct uptake of nitrogen from the soil was 1.4 times greater than uptake via rhizobia $(P<0.001$, Fig. $3 \mathrm{c})$.

\section{Discussion}

Plant roots can absorb soil nutrients directly from underground, and plants also take up soil and atmospheric nutrients indirectly via microbial symbionts in a rhizosphere. In this context, we know little about how insect herbivory affects nutrient uptake via these two pathways. We demonstrated (1) inorganic soil nitrogen and nitrogen uptake by the plants from the soil were decreased in the presence of aphids, (2) nitrogen uptake via rhizobia was decreased in the aphid-infected plants, and (3) the negative impact of the aphids on soil nitrogen uptake was greater than uptake via rhizobia. Our results clearly illustrated that herbivorous insects negatively influence both pathways of nutrient uptake in plants, directly from the soil and indirectly via symbiotic microbes, and that the negative effect of insect herbivory on the direct pathway from soil is greater than the indirect pathway via symbionts.

\section{Aphid effects on soil nitrogen and soil nitrogen uptake}

In our experiment, aphids reduced the inorganic soil nitrogen sevenfold (Fig. 2b). 
Because total soil nitrogen did not differ between the aphid-free and aphid-infected treatments (Fig. 2a), the aphids would not have added (or released) nitrogen to the soil. Instead, the decrease in inorganic soil nitrogen may be due to microbial nitrogen immobilization in soil, by adding of a large amount of aphid honeydew (Schmidt et al., 1997). The aphid-infected treatment showed that on average, $13 \mathrm{mg}$ of sugars from honeydew were added to $3.14 \times 10^{-4} \mathrm{~m}^{2}$ soil area every day (equivalent to $41 \mathrm{~g} \mathrm{~m}^{-2}$ per day, Fig. 1). This amount is large enough to induce microbial nitrogen immobilization, although it may be underestimated due to the potential presence of undetected macromolecular oligosaccharides in honeydew. For example, Dighton (1978) experimentally estimated the impact of honeydew on free-living soil microbes using a sugar solution that mimicked aphid honeydew. The addition of $50 \mathrm{~g} \mathrm{~m}^{-2}$ of artificial honeydew per day caused a $30 \%$ increase in soil fungal biomass and a $300 \%$ increase in bacterial biomass. Schmidt et al. (1997) reported that the addition of $0.8-1.6 \mathrm{mg} \mathrm{day}^{-1}$ of glucose, on the other hand, into soil induced microbial immobilization and decreased the inorganic nitrogen content by $50 \%$ (the average amount of glucose added to the soil as honeydew in our experiment was $2.3 \mathrm{mg} \mathrm{day}^{-1}$ ). Although other mechanisms, such as root exudation, might decrease inorganic soil nitrogen (Paterson, 2003), the available evidence from previous studies supports that the addition of honeydew reduced the inorganic soil nitrogen content by promoting microbial immobilization.

Decreased available soil nitrogen due to microbial immobilization may subsequently influence nitrogen uptake from the soil by the host plants. The xylem sap analysis showed that the flow of xylem sap did not differ between the treatments (Fig. 3a), but the nitrate and amino acid contents of the sap were significantly lower in the aphid-infected treatment than the aphid-free treatment (Fig. 3b). It indicates that the plants were able to equally absorb water from the soil, and thus the nitrate and amino acid 
contents in the xylem sap are likely reflected by the amount of soil inorganic nitrogen. Therefore, we conclude that the aphids reduced the amount of soil inorganic nitrogen but they did not affect the plant's ability to absorb water.

\section{Aphid effects on nitrogen-fixing bacteria}

There is a growing body of evidence that below-ground symbiotic microbes can influence above-ground plant-insect interactions (see Hartley \& Gange, 2009 for a review). In this context, several studies have reported the positive effects of nitrogen-fixing bacteria on above-ground herbivorous insects (Kempel et al., 2009; Katayama et al., 2011ab). For example, Kempel et al. (2009) demonstrated that the rhizobia increased the body weight of lepidopteran caterpillars and the colony size of aphids on clover (Trifolium repens L.). However, effects of above-ground insect herbivory on plant-rhizobia associations have not been explored. In this study, we hypothesized that aphids would affect plant-rhizobia associations by two, but not mutually exclusive, mechanisms: (1) decreasing the inorganic nitrogen concentration by inducing microbial immobilization would reinforce the plant-rhizobia association, and (2) carbon stress in the host plants would weaken the plant-rhizobia association. Our results showed that aphid herbivory decreased the concentration of ureides in xylem sap (Fig. 3b), suggesting that the later mechanism worked more strongly in this system. Leguminous plants need a large amount of photosynthetic carbon, i.e., $6-14 \%$ of the photosynthetic production of the plants, to maintain their mutualistic association with rhizobia (Tate, 2000), whereas aphids consume large amounts of photosynthetic carbon. Because photosynthetic carbon is essential for nitrogen fixation by rhizobia (Rawsthorne et al., 1980), it is likely that the carbon stress caused by aphids has a greater negative effect on the rhizobia-plant association than the positive effect of microbial immobilization. Thus, 
the nitrogen uptake of plants via rhizobia may have decreased in the presence of aphids.

\section{Relative impacts of aphids on nitrogen derived from soil and rhizobia}

The relative impacts of aphids on nitrogen uptake via the two pathways, we found that although aphids negatively affected the both pathways, the strength of the impact on direct uptake via plant roots was significantly greater than indirect uptake via rhizobia (Fig. 3c). The mechanism of the aphid effect on the nitrogen uptake from the soil may be due to induced microbial nitrogen immobilization by adding aphid honeydew, resulting in a decrease in available soil nitrogen. In contrast, aphids may affect nitrogen uptake via rhizobia in a more complicated way, reflecting both microbial immobilization and carbon stress on the plant-rhizobia association. Because microbial immobilization positively affects the association but carbon stress negatively does, the net effect of aphids depends on the relative importance of these two mechanisms. Our results suggest offset of the negative effect of carbon stress by the positive effect of microbial immobilization.

The availability of nitrogen to herbivores differs, depending on its form (Wilson \& Stinner, 1984; Katayama et al., 2010; Thamer et al., 2011). Ureides, the major form of nitrogen taken up via the rhizobia, are enzymatically degraded by allantoinase in above-ground plant tissues, and the nitrogen is used for amino acid synthesis (Matsumoto et al., 1977). However, insects lack allantoinase unless they harbour endosymbionts that can synthesize it (Cochran, 1975). As a result, plant tissues with a higher proportion of ureides may have less nitrogen available to herbivorous insects (Wilson \& Stinner, 1984). In addition, lack of plant nitrogen leads to a decrease in the abundance, species richness, and diversity of herbivorous insects (Katayama et al., 2011a) as herbivorous insects use nitrogen in plant tissue for survival and reproduction (Mattson \& Scriber, 1987). If aphids simultaneously decrease the total nitrogen in plant tissue and increase the proportion of 
ureides- $\mathrm{N}$, the aphids on the plants may negatively influence more than other insect herbivores.

\section{Ecosystem function of aphids}

Insect excrement can drive soil nutrient dynamics (Weisser \& Siemann, 2004), and different $\mathrm{C} / \mathrm{N}$ ratios of the excrement influence differently plant growth (Kagata \& Ohgushi, 2012). Honeydew is extremely carbon rich but nitrogen poor because the sugars in honeydew is 100 times more than the amino acid concentration (Dixon, 1998; Katayama et al., 2013b). Aphids are a dominant component in a terrestrial ecosystem, and their production of honeydew may have a prominent ecosystem function, affecting negatively the availability of inorganic soil nitrogen to plants, and suppressing rhizobial activity and thus decreasing plant nitrogen uptake via rhizobia. These negative impacts of aphids on nitrogen uptake would influence other ecosystem processes such as litter decomposition. Litter nitrogen content importantly affects decomposition rates; litter with a low $\mathrm{C} / \mathrm{N}$ ratio is more easily mineralized by microbial decomposers (Manzoni et al., 2008). The reduction in nitrogen uptake by aphid-infected plants would produce litter with a high $\mathrm{C} / \mathrm{N}$ ratio. As a result, nitrogen mineralization in the litter would occur more slowly (Katayama et al., 2013a). These findings suggest that aphids can negatively affect ecosystem nitrogen fluxes. Future work need to compare the effects of aphids and other herbivorous insects on plant nutrient uptake in plant-rhizobia symbiotic systems, which will provide a critical insight into how insects shape below- and above-ground nutrient dynamics (van der Putten et al., 2001; Wardle et al., 2004).

\section{Acknowledgements}

We thank Prof. T. Murai of Utsunomiya University, Tochigi Prefecture, for 
providing the aphid strains that we used in our research. We thank Drs H. Kagata, S. Utsumi, and Y. Ando for helpful advice. The Ministry of Education, Culture, Sport, Science and Technology of Japan (MEXT) financially supported A. O. Silva during this study in Japan. This study was supported by a Grant-in-Aid for Scientific Research from the Ministry of Education, Culture, Sports, Science, and Technology to T. Ohgushi (B-20370010) and to O. Kishida (no. 24370004), by the Global COE program (A06) of Kyoto University, and by a JSPS Research Fellowship for Young Scientists to N. Katayama. 


\section{References}

Cataldo, D.A., Haroon, M., Schrader, L.E. \& Youngs, V.L. (1975) Rapid calorimetric determination of nitrate in plants tissues by nitration of salicylic acid. Communications in Soil Science and Plant Analysis, 6, 71-80.

Chapman, S.K., Hart, S.C., Cobb, N.S., Whitham, T.G. \& Koch, G.W. (2003) Insect herbivory increases litter quality and decomposition: an extension of the acceleration hypothesis. Ecology, 84, 2867-2876.

Cochran, D.G. (1975) Excretion in insects. Insect Biochemistry and Function (ed. by D.J. Candy and B.A. Kilby), pp. 177-282. Chapman and Hall Ltd, London, U.K.

Dessureault-Rompré, J., Nowack, B., Schulin, R. \& Luster, J. (2007) Spatial and temporal variation in organic acid anion exudation and nutrient anion uptake in the rhizosphere of Lupinus albus L. Plant and Soil, 301, 123-134.

Dighton, J. (1978) Effects of synthetic lime aphid honeydew on populations of soil organisms. Soil Biology and Biochemistry, 10, 369-376.

Dixon, A.F.G. (1998) Aphid Ecology. Chapman and Hall, London, U.K.

Frost, C.J. \& Hunter, M.D. (2004) Insect canopy herbivory and frass deposition affect soil nutrient dynamics and export in oak mesocosms. Ecology, 85, 3335-3347.

Gehring, C.A. \& Whitham, T.G. (1994) Interactions between aboveground herbivores and the mycorrhizal mutualists of plants. Trends in Ecology and Evolution, 9, 251-255.

Giller, K.E. (2001) Nitrogen Fixation in Tropical Cropping Systems, 2nd ed. CABI Publishing. Wallingford, U.K.

Grier, C. \& Vogt, D.J. (1990) Effects of aphid honeydew on soil nitrogen availability and net primary production in an Alnus rubra plantation in western Washington. Oikos, $\mathbf{5 7 , 1 1 4 - 1 1 8 . ~}$

Hartley, S.E. \& Gange, A.C. (2009) Impacts of plant symbiotic fungi on insect 
herbivores: mutualism in a multitrophic context. Annual Review of Entomology, 54, $323-342$.

Hedges, L.V., Gurevitch, J. \& Curtis, P.S. (1999) The meta-analysis of response ratios in experimental ecology. Ecology, 80, 1150-1156.

Herridge, D.F. (1984) Effect of nitrate and plant development on the abundance of nitrogenous solutes in root-bleeding and vacuum-extracted exudates of soybean. Crop Science, 24, 173-179.

Hunter, M.D. (2001) Insect population dynamics meets ecosystem ecology: effects of herbivory on soil nutrient dynamics. Agricultural and Forest Entomology, 3, 77-84.

Kagata, H. \& Ohgushi, T. (2012) Positive and negative impacts of insect frass quality on soil nitrogen availability and plant growth. Population Ecology, 54, 75-82.

Karban, R. \& Baldwin, I.T. (1997) Induced Responses to Herbivory. Univ of Chicago Press, Chicago, Illinois.

Katayama, N., Nishida, T., Zhang, Z.Q. \& Ohgushi, T. (2010) Below-ground microbial symbiont enhances plant susceptibility to a spider mite through change in soybean leaf quality. Population Ecology, 52, 499-506.

Katayama, N., Silva, A.O., Kishida, O. \& Ohgushi, T. (2003a) Aphids decelerate litter nitrogen mineralization through changes in litter quality. Ecological Entomology, 38, $627-630$

Katayama, N., Tsuchida, T., Hojo, M.K. \& Ohgushi, T. (2013b) Aphid genotype determines intensity of ant-attendance: Do endosymbionts and honeydew composition matter? Annals of Entomological Society of America, 106, 761-770.

Katayama, N., Zhang, Z.Q. \& Ohgushi, T. (2011a) Community-wide effects of below-ground rhizobia on above-ground arthropods. Ecological Entomology, 36, $43-51$. 
Katayama, N., Zhang, Z.Q. \& Ohgushi, T. (2011b) Belowground rhizobia positively affect abundances of aboveground sap feeding and leaf chewing herbivores. Journal of Plant Interactions, 6, 173-174.

Kay, A.D., Mankowski, J. \& Hobbie, S.E. (2008) Long-term burning interacts with herbivory to slow decomposition. Ecology, 89, 1188-1194.

Kempel, A., Brandl, R. \& Schädler, M. (2009) Symbiotic soil microorganisms as players in aboveground plant-herbivore interactions - the role of rhizobia. Oikos, 118, 634640.

Lovett, G.M. \& Ruesink, A.E. (1995) Carbon and nitrogen mineralization from decomposing gypsy moth frass. Oecologia, 104, 133-138.

Macedo, T.B., Bastos, C.S., Higley, L.G., Ostlie, K.R. \& Madhavan, S. (2003) Photosynthetic responses of soybean to soybean aphid (Homoptera: Aphididae) injury. Journal of Economic Entomology, 96, 188-193.

Manzoni, S., Jackson, R.B., Trofymow, J.A. \& Porporato, A. (2008) The global stoichiometry of litter nitrogen mineralization. Science, 321, 684-686.

Matsumoto, T., Yatazawa, M. \& Yamamoto, Y. (1977) Incorporation of ${ }^{15} \mathrm{~N}$ into allantoin in nodulated soybean plants supplied with ${ }^{15} \mathrm{~N}_{2}$. Plant and Cell Physiology, 18, $459-462$.

Mattson, W.J. \& Scriber, J.M. (1987) Nutritional ecology of insect folivores of woody plants: nitrogen, water, fiber, and mineral considerations. Nutritional Ecology of Insects, Mites, Spiders, and Related Invertebrates (ed. by F. Slansky and J.G. Rodrigues), pp. 105-146. John Wiley and Sons, New York, New York.

McClure, P.R. \& Israel, D.W. (1979) Transport of nitrogen in the xylem of soybean plants. Plant Physiology, 64, 411-416.

Nishida, T., Izumi, N., Katayama, N. \& Ohgushi, T. (2009) Short-term response of 
arbuscular mycorrhizal association to spider mite herbivory. Population Ecology, 51, 329-334.

Ohgushi, T. (2005) Indirect interaction webs: herbivore-induced effects through trait change in plants. Annual Review of Ecology, Evolution, and Systematics, 36, 81-105.

Paterson, E. (2003) Importance of rhizodeposition in the coupling of plant and microbial productivity. European Journal of Soil Science, 54, 741-750.

Patriarca, E.J., Taté, R. \& Iaccarino, M. (2002) Key role of bacterial $\mathrm{NH}_{4}{ }^{+}$metabolism in rhizobium-plant symbiosis. Microbiology and Molecular Biology Reviews, 66, 203-222.

Rawsthorne, S., Minchin, F.R., Summerfield, R.J., Cookson, C. \& Coombs, J. (1980) Carbon and nitrogen metabolism in legume root nodules. Phytochemistry, 19, 341-355.

Schmidt, I.K., Michelsen, A. \& Jonasson, S. (1997) Effects of soil labile carbon on nutrient partitioning between an arctic graminoid and microbes. Oecologia, 112, $557-565$.

Schowalter, T.D. (2000) Insect Ecology: an Ecosystem Approach. Academic Press, San Diego, California.

Schweitzer, J.A., Bailey, J.K., Hart, S.C., Wimp, G.M., Chapman, S.K. \& Whitham, T.G. (2005) The interaction of plant genotype and herbivory decelerate leaf litter decomposition and alter nutrient dynamics. Oikos, 110, 133-145.

Seastedt, T.R. \& Crossley, D.A.Jr. (1984) The influence of arthropods on ecosystems. BioScience, 34, 157-161.

Smith, S.E. \& Read, D.J. (1997) Mycorrhizal Symbiosis. Academic Press, San Diego, California.

Stadler, B., Michalzik, B. \& Muller, T. (1998) Linking aphid ecology with nutrient flux in 
a coniferous forest. Ecology, 79, 1514-1525.

Stadler, B., Mühlenberg, E. \& Michalzik, B. (2004) The ecology driving nutrient fluxes in forest. Insects and Ecosystem Function. (ed. by W.W. Weisser and E. Siemann), pp. 213-239. Springer-Verlag, Berlin, Germany.

Streeter, J.G. (1979) Allantoin and allantoic acid in tissues and stem exudate from field-grown soybean plants. Plant Physiology, 63, 478-480.

Tate, R.L.III (2000) Soil Microbiology, 2nd ed. John Wiley and Sons, New York, New York.

Thamer, S., Schädler, M., Bonte, D. \& Ballhorn, D.J. (2011) Dual benefit from a belowground symbiosis: nitrogen fixing rhizobia promote growth and defense against a specialist herbivore in a cyanogenic plant. Plant and Soil, 341, 209-219.

Thomas, A.L. \& Sodek, L. (2006) Amino acid and ureide transport in the xylem of symbiotic soybean plants during short-term flooding of the root system in the presence of different sources of nitrogen. Brazilian Journal Plant Physiology, 18, 333-339.

van der Putten, W.H., Vet, L.E.M., Harvey, J.A. \& Wackers, F.L. (2001) Linking aboveand belowground multitrophic interactions of plants, herbivores, pathogens, and their antagonists. Trends in Ecology and Evolution, 16, 547-554.

Wang, C.L., Siang, N.I., Chang, G.S. \& Chu, H.F. (1962) Studies on the soybean aphid Aphis glycines Matsumura. Acta Entomologica Sinica, 11, 31-44.

Wardle, D.A. (1992) A comparative assessment of factors which influence microbial biomass carbon and nitrogen levels in soil. Biological Reviews, 67, 321-358.

Wardle, D.A. (2002) Communities and Ecosystems: Linking the Aboveground and Belowground Components. Princeton Univ. Press, Princeton, New Jersey.

Wardle, D.A., Bardgett, R.D., Klironomos, J.N., Setälä, H., van der Putten, W.H. \& Wall, 
D.H. (2004) Ecological linkages between aboveground and belowground biota. Science, 304, 1629-1633.

Weisser, W.W. \& Siemann, E. (2004) Insects and Ecosystem Function. Springer-Verlag, Berlin, Germany.

Wilson, K.G. \& Stinner, R.E. (1984) A potential influence of rhizobium activity on the availability of nitrogen to legume herbivores. Oecologia, 61, 337-341.

Young, E.G. \& Conway, C.F. (1942) On the estimation of allantoin by the Rimini-Schryver reaction. The Journal of Biological Chemistry, 142, 839-853. 


\section{Figure legends}

Fig. 1. Total sugar amount on the aluminium foil discs two weeks and four weeks after aphid inoculation. Different letters indicate a significant difference between treatments (Tukey-Kramer test; $P<0.05$ ). Error bars show SE.

Fig. 2. (a) Total nitrogen and (b) inorganic nitrogen (ammonium-N + nitrate-N) concentrations in soil in the aphid-free and aphid-infected treatments. ${ }^{*} P<0.05$, $t$-test. Error bars show SE.

Fig. 3. (a) Xylem sap flow and (b) concentrations of nitrogen derived from soil (nitrate-N + amino acid-N) and from rhizobia (ureide-N) in xylem sap. $* P<0.025,{ }^{*} P<$ $0.001, t$-test. Error bars show SE. (c) Magnitude of the aphid effect, expressed as the $\log$ response ratio, on the relative amounts of nitrogen derived from soil and nitrogen from rhizobia. $* * * P<0.001, t$-test. Error bars show $95 \% \mathrm{CL}$. 


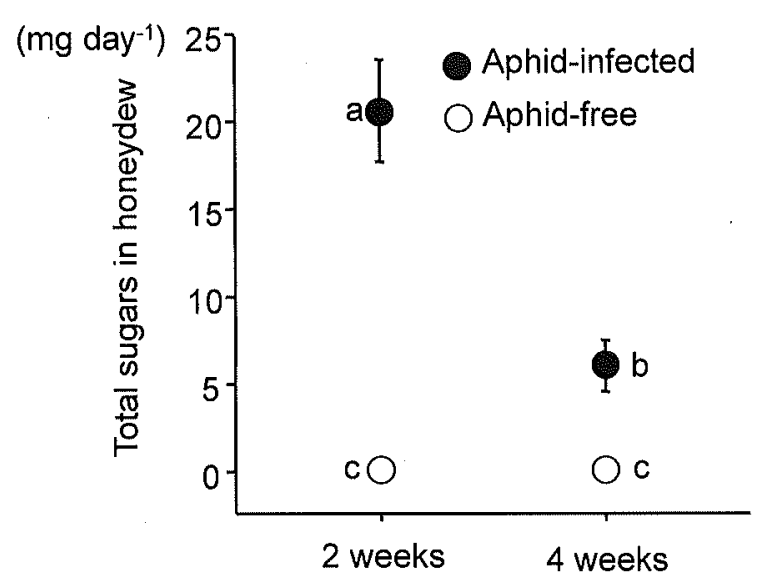

After aphid inoculation

(weeks)

Katayama et al. Fig. 1 

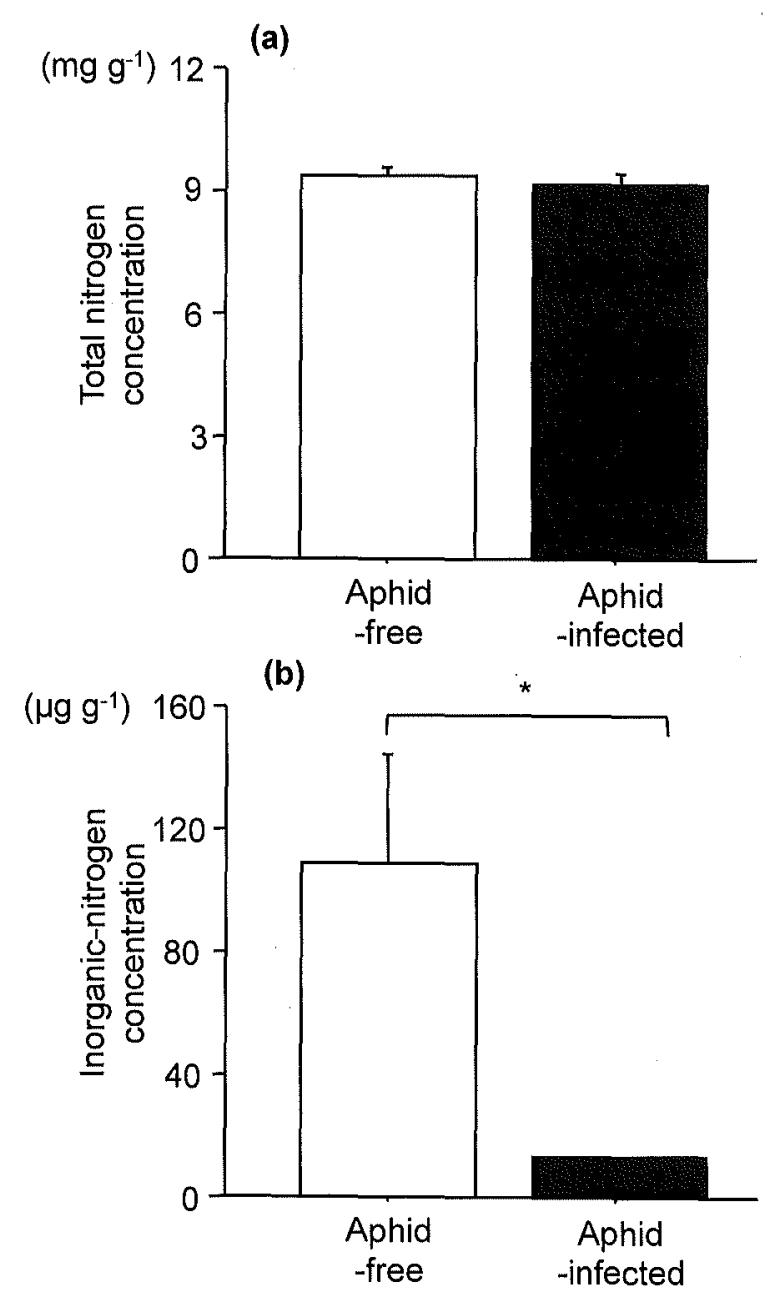

Katayama et al. Fig. 2 
(a)

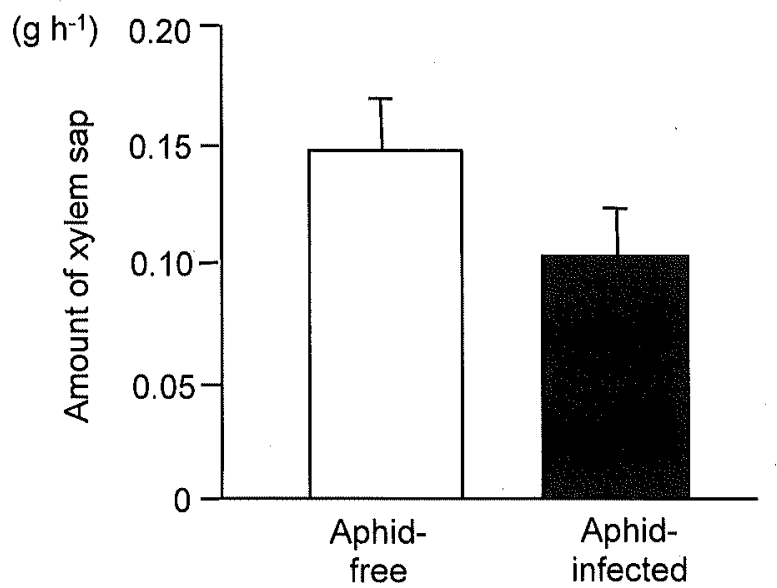

(b)

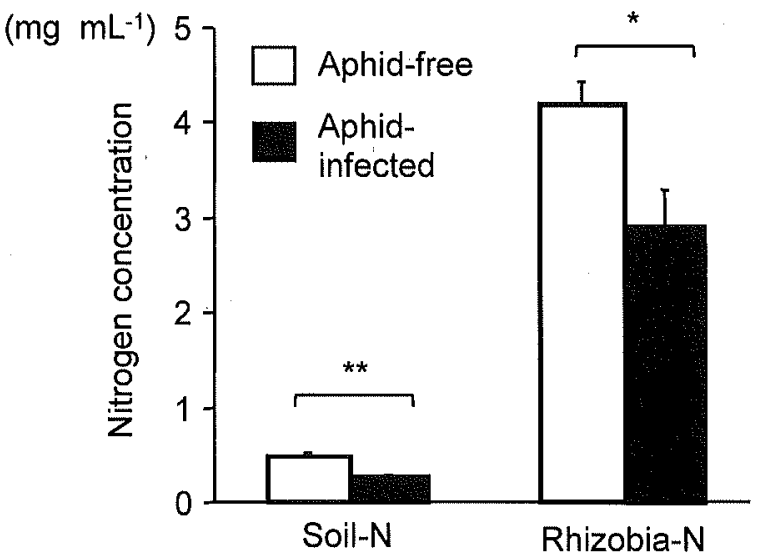

(c)

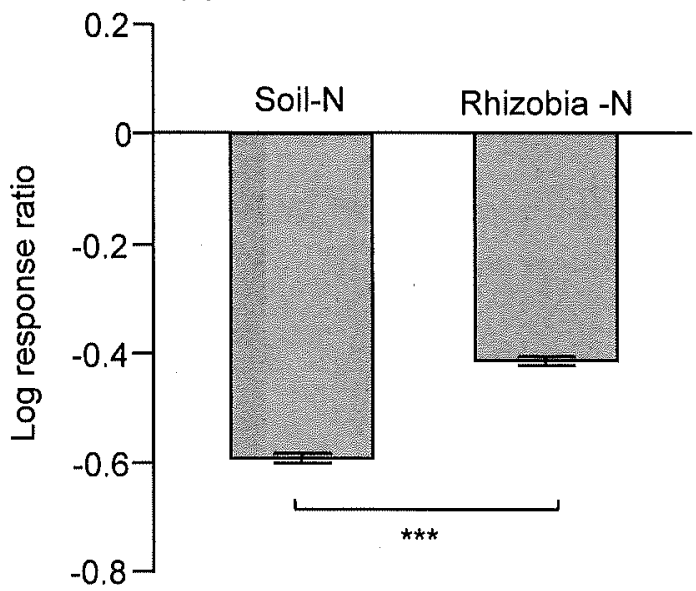

Katayama et al. Fig. 3 